\title{
Rat paw oedema modeling and NSAIDs: Timing of effects
}

\author{
H.H. Cong*, V.N. Khaziakhmetova and L.E. Zigashina \\ Kazan Federal (Volga Region) University, Department of Basic and Clinical Pharmacology, Kazan, \\ Russia
}

*Corresponding author. E-mail: conghonghanh@yahoo.com

BACKGROUND: Non-steroidal anti-inflammatory agents (NSAIDs), steroids and representatives of other pharmacological groups $[1,2]$ are widely used for pharmacological regulation of inflammation. However, their anti-inflammatory effects are accompanied by serious adverse reactions $[3,4]$. There was a hope that newer NSAIDs, selective inhibitors of COX-2, would be safer, but their longer-term use appeared to cause an increased risk of heart attacks and stroke [5]. Carrageenan rat paw oedema model is traditionally used for search and development of new NSAIDs with assessment of effects after 3 to 5 hours after oedema induction $[6,7]$, neglecting longer-term effects [8].

OBJECTIVE: To compare effects of traditional NSAIDs (indomethacin, naproxen) on the development, duration and intensity of carrageenan rat paw oedema.

METHODS: Carrageenan paw oedema was induced in 18 rats by sub-plantar injection into the right hind paw of the animals of $0.1 \mathrm{ml}$ of $1 \%$ aqueous gel of carrageenan- $\lambda$ (22049 SIGMA $\lambda$-Carrageenan plant-mucopolysaccharide, Sigma-Aldrich). We assessed the intensity of the oedema development and its duration by measurements of rat paw volume using plethysmometer 37140 (UgoBasile, Italy). Measurements were made prior to induction of oedema (base-line volume) and at 1, 2, 3, 4, 5, 24, 48, $72,96,120,144,168$ and 192 hours after sub-plantar carrageenan injection. Calculating the percentage of increase in paw volume assessed the intensity of the oedema. The base-line paw volume was taken for $100 \%$.

Animals were divided into 3 groups of 6 rats each; group 1: control (solvent); group 2: naproxen $15 \mathrm{mg} / \mathrm{kg}$ and group 3: indomethacin $10 \mathrm{mg} / \mathrm{kg}$. These doses are known as ED50 (effective doses 50) on carrageenan rat paw oedema with single-dose NSAIDs administration [9]. To get the most accurate estimate of the intensity of the simulated by carrageenan inflammatory response and the potential effects of some NSAIDs with their longer-term use we calculated areas under the curve «increase in paw volume - time» using standard method of numerical integration - trapezoidal method. Statistical analysis was performed using Microsoft Office Excel 2007 with the calculation of arithmetic means $\mathrm{M}$, their standard deviations $(\delta)$ and standard errors $(\mathrm{m})$. We applied Student's $t$-test and accepted as significant the differences with $P$ values equal to or less than 0.05 .

RESULTS: The inflammatory reaction induced by carrageenan, developed in a form of swelling/ oedema with an increase in the rat paw volume up to $55 \%$ of the baseline volume. The maximum volume of oedema was observed in the control group at $3 \mathrm{~h}$ after the injection of carrageenan, which is in accordance with the literature data on the development of carrageenan paw edema in rats [10, 11]. Naproxen at a dose of $15 \mathrm{mg} / \mathrm{kg}$ showed anti-inflammatory activity at 1, 2, 3, 4 and 5 hours after 
administration of carrageenan with suppression of oedema development by 59, 81, 73, 60 and 39\% $(p=0.03 ; 0.001 ; 0.001 ; 0.001$ and 0.01$)$, respectively. There was no oedema inhibition by naproxen at later time-points. Indomethacin at a dose of $10 \mathrm{mg} / \mathrm{kg}$ showed anti-inflammatory effect at 2, 3, 4, and 5 hours after carrageenan oedema induction with inhibition of oedema development by 54,54 , 54 and 33\% ( $p=0.01,0.004,0.001$ and 0.01 ) respectively. Again there was no oedema inhibition by indomethacin at the later time-points.

When comparing the calculated areas under the curve «increase in paw volume - time» we found no differences between the values of control and study groups: naproxen $(15 \mathrm{mg} / \mathrm{kg})$ and indomethacin $(10$ $\mathrm{mg} / \mathrm{kg}$ ). We think that these values of areas under the curve «increase in paw volume - time» represent the total inflammatory reaction induced by carrageenan and need to be used for the assessment of future potential anti-inflammatory agents which should not only produce short-term symptomatic oedema suppression, but change the nature of the oedema response, potentially with alternative mechanisms of action. Our experimental findings are in accordance with the well-known lack of effects of NSAIDs on the outcomes of chronic inflammatory diseases [12]. This may be due to the fact that they suppress the development and symptoms of inflammation at the early stages, but the reaction to inflammatory stimuli develops fully over the longer period of time and takes its full course nonetheless. This proves that traditional modeling approaches to future potential anti-inflammatory agents development needs re-assessment.

CONCLUSIONS: Single-dose administration of naproxen $(15 \mathrm{mg} / \mathrm{kg})$ or indomethacin $(10 \mathrm{mg} / \mathrm{kg})$ exerts decrease in rat paw oedema volume at no later than 5 hours after oedema induction by carrageenan. Evaluating anti-inflammatory activity by the areas under the curve «increase in paw volume - time» proves that a single-dose NSAID's administration has no effect on the inflammatory response when evaluated not by single time-point index (at 3 or 5 hours), but by assessing the oedema development and duration over 192 hours (8 days).

Keywords: Rat paw oedema, NSAIDs, timing of effects, anti-inflammatory

Conflict of interest statement: We declare that we have no conflict of interest. This work was funded by the subsidy allocated to Kazan Federal University for the state assignment in the sphere of scientific activities.

\section{References}

[1] Hardman JG, Limbird LE, Gilman AG, editors. Goodman \& Gilman's The Pharmacological Basis of Therapeutics. 10th ed. New York: McGraw-Hill; 2001.

[2] Khaziakhmetova VN, Valeeva IH, Ziganshina LE. Anti-inflammatory effects of amitriptyline, diazepam and mebicar. Experimental and Clinical Pharmacology. 2011;12(74):19-22.

[3] Aronson JK. Meyler's side effects of analgesics and anti-inflammatory drugs. Amsterdam: Elsevier; 2009.

[4] Lanas A, Garcia-Tell G, Armada B, Oteo-Alvaro A. Prescription patterns and appropriateness of NSAID therapy according to gastrointestinal risk and cardiovascular history in patients with diagnoses of osteoarthritis. BMC Med. 2011;9:38.

[5] Bresalier RS, Sandler RS, Quan H, Bolognese JA, Oxenius B, Horgan K, et al. Cardiovascular events associated with rofecoxib in a colorectal adenoma chemoprevention trial. N Engl J Med 2005;352:1092-102.

[6] Haider S, Nazreen S, Alam MM, Gupta A, Hamid H, Alam MS. Anti-inflammatory and anti-nociceptive activities of ethanolic extract and its various fractions from Adiantum capillus veneris Linn. Journal of Ethnopharmacology. 2011;138:741-7.

[7] Shang X, Wang J, Li M, Miao X, Pan H, Yang Y, Wang Y. Antinociceptive and anti-inflammatory activities of Phlomis umbrosa Turcz extract. Fitoterapia. 2011;82(4):716-21.

[8] Cong HH, Khaziakhmetova VN, Ziganshina LE. Modeling inflammatory edema: Are the models interchangeable. Experimental and clinical pharmacology. 2015;78(7):24-31.

[9] Mironov AN. Guidelines for preclinical studies of drugs. Moscow: Grief and K; 2012.

[10] Chao M, Jang JM. Animal models of pain. Neuromethods. 2011;49:23-40.doi 10.1007 / 978-1-60761-880-5_2, C) Springer Science + Business Media, LLC 2011

[11] Lee OI, Crosby G. Halothane effect on formalin- induced paw edema and flinching in rat. J Korean Med Sci. 1999;14:348 .

[12] Lanas A, Tornero J, Zamorano JL. Assessment of gastrointestinal and cardiovascular risk in patients with osteoarthritis who require NSAIDs: the LOGICA study. Ann Rheum Dis. 2010;69:1453-8. 